\title{
The prevalence, awareness, treatment, and control of hypertension among adults: the first cross- sectional national population-based survey in Laos
}

This article was published in the following Dove Medical Press journal: Vascular Health and Risk Management

\author{
Supa Pengpid ${ }^{1,2}$ \\ Manithong Vonglokham ${ }^{3}$ \\ Sengchanh Kounnavong ${ }^{4,5}$ \\ Vanphanom Sychareun ${ }^{6}$ \\ Karl Peltzer 7,8 \\ 'ASEAN Institute for Health \\ Development, Mahidol University, \\ Salaya, Nakhon Pathom, Thailand; \\ ${ }^{2}$ Office of the Deputy Vice Chancellor \\ (Research and Innovation), North \\ West University, Potchestroom, South \\ Africa; ${ }^{3}$ Department of Health Policy \\ and Health System Research, Lao \\ Tropical and Public Health Institute, \\ Vientiane, Laos; ${ }^{4}$ Lao Tropical and \\ Public Health Institute, Vientiane, \\ Laos; ${ }^{5}$ Ministry of Health, Vientiane, \\ Laos; ${ }^{6}$ Faculty of Postgraduate \\ Studies, University of Health Sciences, \\ Ministry of Health, Vientiane, Laos; \\ ${ }^{7}$ Department for Management of \\ Science and Technology Development, \\ Ton Duc Thang University, Ho Chi \\ Minh City, Vietnam; ${ }^{8}$ Faculty of \\ Pharmacy, Ton Duc Thang University, \\ Ho Chi Minh City, Vietnam
}

Correspondence: Karl Peltzer Department for Management of Science and Technology Development, Ton Duc Thang University, 19 Nguyen Huu Tho Street, Tan Phong Ward, District 7, Ho Chi Minh City, Vietnam

Email karl.peltzer@tdt.edu.vn
Aim: The aim of this study was to determine the national prevalence of hypertension and its awareness, treatment, and control in Laos.

Methods: A national cross-sectional study was conducted in 2013. Using stratified cluster random sampling, 2,543 individuals aged 18-64 years were included from Laos. According to WHO STEPS methodology, questionnaire interview, anthropometric and blood pressure measurements, and biochemistry tests were conducted. Logistic regressions were used to estimate the determinants of hypertension (SBP [and/or DBP] $\geq 140$ [90] $\mathrm{mmHg}$ or use of antihypertensive medications).

Results: Overall, $20.0 \%$ of the population had hypertension, $18.5 \%$ among men and $21.1 \%$ among women. Among hypertensives, $29.4 \%$ were aware, $18.2 \%$ were currently using antihypertensive medication, and $16.7 \%$ had controlled their blood pressure $(<140 \mathrm{mmHg}$ SBP and DBP $<90 \mathrm{mmHg}$ ). In fully adjusted models in both men and women, older age and general obesity were positively associated with hypertension. In addition, among men having raised cholesterol and completed primary education, and among women central obesity and hazardous or harmful alcohol users were positively associated with hypertension.

Conclusion: The study found a significant prevalence of hypertension and low awareness, treatment, and control rates of hypertension among adults in Laos.

Keywords: hypertension, awareness, treatment, control, determinants, population survey, Laos

\section{Introduction}

In low- and middle-income countries, the health burden of chronic noncommunicable diseases (NCDs) have been increasing, ${ }^{1}$ including in Southeast Asian countries, such as in Laos. ${ }^{2}$ NCDs and their risk factors, such as hypertension, stroke, and diabetes, are largely contributing to morbidity and mortality of the Lao population. ${ }^{3-5}$ In a 2008 Lao STEPS survey, conducted only in one municipality (Vientiane), a hypertension prevalence of $22.3 \%$ among 25 - to 64 -year olds (24.9\% among men and $20.5 \%$ among women) was found. ${ }^{3}$ There is a lack of national data on the prevalence and associated factors of hypertension in Laos.

Increasing trends have been shown in the prevalence of hypertension in high-, middle-, and low- income countries. ${ }^{2}$ Between 1975 and 2015, "mean SBP might have increased in men and women in southeast Asia". ${ }^{6}$ In southeast Asia, three-quarters or more of the rise in raised blood pressure is attributable to population growth and aging, and the remainder is due to an increase in prevalence. ${ }^{6}$ In other national populationbased surveys in Southeast Asia, the prevalence of hypertension was in Cambodia 
$15.3 \%$ (25-64 years in 2010), ${ }^{7}$ in Malaysia $43.5 \%$ ( $\geq 30$ years in 2011), ${ }^{8}$ in Myanmar 30.1\% (15- to 64-year olds in 2009), ${ }^{9}$ in Sri Lanka $23.7 \%$ ( $\geq 18$ years in $2005-2006),{ }^{10}$ Thailand $22.0 \%$ (15 years and older in 2004), ${ }^{11}$ and Vietnam $25.1 \%$ ( $\geq 25$ years in 2002-2008). ${ }^{12}$

Although hypertension is a preventable disease, recent studies found, however, a low prevalence of antihypertensive medication treatment. In the 2008 Lao STEP survey, $83.8 \%$ of the people diagnosed as hypertensive were not on medication. ${ }^{3}$ In the previously reported national population-based surveys in China, $42.6 \%$ were aware of their hypertension status and $34.1 \%$ received antihypertensive treatment, ${ }^{13}$ in Iran 34\% were aware and $24.8 \%$ were treated, ${ }^{14}$ in Thailand $30.2 \%$ were aware, ${ }^{11}$ and in Vietnam $48.4 \%$ were aware and $29.5 \%$ received treatment. ${ }^{12}$ In a community study with participants (35-70 years) from 17 mainly low- and middle-income countries, $46.5 \%$ were aware of their hypertension diagnosis and $32.5 \%$ were treated. ${ }^{15}$ These studies indicate the very important need for the improvement in the diagnosis and treatment of hypertension. ${ }^{15}$

Various risk factors have been found to be linked with hypertension, including socio-demographics (older age, women or men, lower education level, lower household income), ${ }^{9-12,14-16}$ urban residence, ${ }^{9,12}$ and other risk factors including body weight status and health risk behavior and psychosocial stress and support. Higher body mass index (BMI) has been found to be positively ${ }^{9,13,15-17}$ and underweight status negatively ${ }^{10}$ associated with hypertension. Other metabolic risk factors for hypertension include diabetes ${ }^{17-19}$ and dyslipidemia or low high-density lipoproteins. ${ }^{19,20}$ Various dietary behaviors, including insufficient fruit and vegetable intake, ${ }^{21-23}$ and consumption of fatty foods $\mathrm{s}^{24,25}$ and fast foods ${ }^{26}$ increased the odds of having hypertension. A number of studies found an association between physical inactivity, ${ }^{9,13,27}$ smoking, ${ }^{28}$ problem, or habitual drinking ${ }^{13,29}$ and hypertension. The aim of this study was to assess the prevalence of hypertension and its awareness, treatment, and control in Laos.

\section{Methods}

\section{Study design and participants}

A multi-stage cluster survey (villages and urban/rural) using WHO STEPS methodology was conducted among adults (18-64 years) in Laos in 2013; the response rate was 98\%. More details regarding the survey are discussed in a study by Vonglokham et al. ${ }^{30}$

Written informed consent was obtained from study participants and the research protocol was approved by the "National Ethical Committee for Health Research" (Deliberation No 019/NECHR of 03 January, 2013) in Laos.

\section{Measures}

According to WHO STEPS methodology, ${ }^{31}$ interviews, anthropometric and blood pressure measurements, and biochemistry tests were conducted..$^{30}$ Interview questions included dietary behavior (fruit and vegetable consumption), alcohol use, tobacco use, physical activity, and sociodemographic variables. Based on the "Global Physical Activity Questionnaire", ${ }^{32}$ the levels of physical activity were classified into low, moderate, and high. Participants consuming $>7$ (women) or $>14$ (men) standard alcoholic units in the past week were considered hazardous or harmful alcohol users. ${ }^{33}$

BMI was classified according to Asian criteria: normal weight $\left(18.5\right.$ to $\left.<23.0 \mathrm{~kg} / \mathrm{m}^{2}\right)$, overweight $(23.0$ to $<25.0 \mathrm{~kg}$ / $\mathrm{m}^{2}$ ), and obese $\left(25+\mathrm{kg} / \mathrm{m}^{2}\right) .{ }^{34}$ Central obesity was classified as "waist circumference (WC) $90 \mathrm{~cm}$ or more in men and $80 \mathrm{~cm}$ or more in women". ${ }^{35}$ Each of the three SBP and DBP readings were averaged arithmetically. Hypertension was defined as "SBP $\geq 140 \mathrm{mmHg}$ and/or DBP $\geq 90 \mathrm{mmHg}$ or where the participant is currently on antihypertensive medication". ${ }^{36}$

Raised cholesterol was classified as "raised fasting total cholesterol $\geq 5.0 \mathrm{mmol} / \mathrm{L}$ or currently on medication for raised cholesterol" ${ }^{30}$ Raised fasting blood glucose was classified as "blood glucose $\geq 6.1 \mathrm{mmol} / \mathrm{L}$ and/or on diabetes medication". 30

\section{Data analysis}

Post-stratification weighting accounted for population distribution by districts, gender, and age groups from the national population census projection for 2012 based on the Laos National Census conducted in 2005. ${ }^{30}$ Individual weight was determined with the inverse of the probability of selection for each respondent, which was considered as the weight for the individual household..$^{30}$

Descriptive statistics on frequency, weighted prevalence, and $95 \%$ CI was used for sociodemographic and risk factor variables. Logistic regression was performed to assess associations between sociodemographics, health variables, and prevalence of hypertension. All analyses were adjusted for the multi-stage sampling design and conducted with STATA software version 14.0 (StataCorp LLC, College Station, TX, USA).

\section{Results}

\section{Sample characteristics}

The total sample included 2,543 individuals aged 18-64 years (women, 59.3\%; mean age, 38.7 years, $\mathrm{SD}=12.8$ ) from Laos. Overall, $20.0 \%$ of the population had hypertension, $18.5 \%$ 
among men and $21.1 \%$ among women, $8.0 \%$ among 18 - to 24-year olds and 33.8\% among 55- to 64-year olds. Among hypertensives, $29.4 \%$ were aware that they had hypertension, which was higher in women $(32.0 \%)$ than in men $(25.0 \%)$. Of the population with hypertension, $18.2 \%$ were currently using antihypertensive medication, and $16.7 \%$ had controlled their blood pressure ( $<140 \mathrm{mmHg}$ and DBP $<90 \mathrm{mmHg}$ ). Mean SBP was $3.7 \mathrm{mmHg}$ higher for men than for women, while mean DBP was $1.2 \mathrm{mmHg}$ higher for women than for men. The prevalence of BMI obesity as well as central obesity was higher in women ( $28.0 \%$ and $39.4 \%$, respectively) than in men (21.4\% and $13.0 \%$, respectively), while the current tobacco use prevalence was significantly higher in men $(56.3 \%)$ than in women (18.5\%) (Tables 1 and 2).

Only $39.9 \%$ of the population sample indicated that they had ever their blood pressure measured by a healthcare worker; this rate increased from $29.4 \%$ among 18 - to 24 -year olds to $47.7 \%$ among 55- to 64-year olds. Of the individuals aware of their hypertension status, half (49.9\%) indicated that they were currently taking antihypertensive medication; this

Table I Sample characteristics

\begin{tabular}{|c|c|c|c|c|c|}
\hline Variables & Variable specification & Total & Men & Women & P-value \\
\hline Sample & $N(\%)$ & 2,543 & $\mathrm{I}, 003(40.7)$ & $\mathrm{I}, 540(59.3)$ & \\
\hline Mean age in years (SD) & Range $18-64$, mean (SD) & $38.7(12.8)$ & $39.9(13.3)$ & $38.0(12.4)$ & $<0.001$ \\
\hline SBP & mmHg, mean (SD) & II9.5 (19.1) & $121.7(18.3)$ & II $8.0(19.4)$ & 0.004 \\
\hline DBP & mmHg, mean (SD) & $77.0(12.5)$ & $76.3(12.0)$ & $77.5(12.8)$ & 0.003 \\
\hline Hypertension & $\%$ & 20.0 & 18.5 & 21.1 & 0.168 \\
\hline Of hypertensives & Aware, \% & 29.4 & 25.0 & 32.0 & $<0.001$ \\
\hline Of hypertensives & Treated, \% & 18.2 & 13.8 & 20.8 & $<0.001$ \\
\hline Of hypertensives & Controlled, \% & 16.7 & 17.3 & 16.4 & 0.822 \\
\hline \multirow[t]{3}{*}{ Education } & None/less than primary, \% & 41.8 & 30.5 & 49.7 & $<0.001$ \\
\hline & Primary, \% & 27.3 & 29.7 & 25.7 & \\
\hline & Secondary or more, \% & 30.8 & 39.8 & 24.6 & \\
\hline \multirow[t]{3}{*}{ Marital status } & Never married, \% & 10.5 & 11.7 & 9.8 & 0.002 \\
\hline & Married or cohabiting, \% & 86.2 & 86.8 & 85.8 & \\
\hline & Separated/divorced/widowed, \% & 3.3 & 1.5 & 4.5 & \\
\hline \multirow[t]{2}{*}{ Employment status } & Employed, \% & 41.6 & 44.8 & 39.8 & 0.078 \\
\hline & Not employed, \% & 58.4 & 55.7 & 60.2 & \\
\hline \multirow[t]{2}{*}{ Ethno-linguistic group } & Lao-Tai, \% & 73.0 & 70.7 & 74.7 & 0.088 \\
\hline & Other, \% & 27.0 & 29.3 & 25.3 & \\
\hline \multirow[t]{2}{*}{ Residence } & Rural, \% & 67.7 & 67.5 & 67.8 & 0.906 \\
\hline & Urban, \% & 32.3 & 32.5 & 32.2 & \\
\hline \multicolumn{6}{|l|}{$\begin{array}{l}\text { Body weight status and health } \\
\text { behavior }\end{array}$} \\
\hline \multirow[t]{4}{*}{ Body mass index } & Normal, \% & 47.5 & 53.4 & 43.5 & $<0.001$ \\
\hline & Underweight, \% & 9.7 & 8.6 & 10.4 & \\
\hline & Overweight, \% & 17.5 & 16.6 & 18.1 & \\
\hline & Obese, \% & 25.3 & 21.4 & 28.0 & \\
\hline Central obesity & $\begin{array}{l}\text { Waist circumference ( } \geq 90 \mathrm{~cm} \text { in } \\
\text { men and } \geq 80 \mathrm{~cm} \text { in women), } \%\end{array}$ & 28.7 & 13.0 & 39.4 & $<0.00$ I \\
\hline Fruit and vegetable consumption & $<5$ servings/day, $\%$ & 86.9 & 86.9 & 86.9 & 0.976 \\
\hline Had meals prepared outside home & Once or more/week, \% & 28.8 & 32.1 & 26.5 & 0.011 \\
\hline Vegetable oil & Used for meals, \% & 67.6 & 66.1 & 68.7 & 0.245 \\
\hline \multirow[t]{3}{*}{ Physical activity } & Low, \% & 13.0 & 6.4 & 17.5 & $<0.001$ \\
\hline & Moderate, \% & 21.8 & 14.5 & 26.8 & \\
\hline & High, \% & 65.2 & 79.1 & 55.7 & \\
\hline Sitting & High ( $\geq 7.5$ hours/day), \% & 3.8 & 2.5 & 4.7 & 0.030 \\
\hline Tobacco use & Current, \% & 33.8 & 56.3 & 18.5 & $<0.001$ \\
\hline Alcohol use & Problem use, \% & 3.6 & 5.2 & 2.5 & $<0.002$ \\
\hline $\begin{array}{l}\text { Raised cholesterol }(\geq 5.0 \mathrm{mmol} / \mathrm{L}) \\
\text { or medication }\end{array}$ & $\%$ & 22.9 & 15.1 & 28.2 & $<0.001$ \\
\hline $\begin{array}{l}\text { Raised fasting blood glucose }(\geq 6.1 \\
\mathrm{mmol} / \mathrm{L}) \text { or medication }\end{array}$ & $\%$ & 7.3 & 5.7 & 8.4 & 0.019 \\
\hline
\end{tabular}


was above $60 \%$ among 18 - to 24 - and 55- to 64-year olds, while this was only $26.7 \%$ among 35 - to 44 -year olds. More than $65 \%$ of participants being aware of their hypertension status were given advise to reduce salt, lose weight, and start or do more exercise, while only $44.2 \%$ overall and $14.7 \%$ among 25- to 34-year olds had been advised to stop using tobacco. More than one in four $(26.7 \%)$ of the participants who were aware of their hypertension status had ever consulted a traditional healer for their hypertension problem, and $12.8 \%$, in particular among older age groups, were currently taking a herbal or traditional remedy for their hypertension. Among participants who were using antihypertensive medication, overall only $17.1 \%$ were controlled; this was the highest among 25- to 34-year olds (40.1\%) and lowest among 35- to 44-year olds $(0.0 \%)$ (Table 3$)$.

Table 2 Prevalence of hypertension by age and sex

\begin{tabular}{|l|l|l|l|}
\hline Variables & Total & Men & Women \\
\hline Age in years & N (\%) & n (\%) & n (\%) \\
\hline I8-24 & $30(8.4)$ & $\mathrm{II}(8.2)$ & $19(8.6)$ \\
$25-34$ & $73(12.0)$ & $18(8.8)$ & $55(13.9)$ \\
$35-44$ & $129(20.7)$ & $42(17.8)$ & $87(22.4)$ \\
$45-54$ & $147(27.5)$ & $58(26.0)$ & $89(28.6)$ \\
$55-64$ & $119(33.8)$ & $50(30.7)$ & $69(37.2)$ \\
All & $498(20.0)$ & $179(18.5)$ & $319(21.1)$ \\
\hline
\end{tabular}

\section{Associations between risk factors and hypertension}

Table 4 shows associations (ORs) between independent variables and the prevalence of hypertension among men and women, separately. In fully adjusted models for both men and women, older age and general obesity were positively associated with hypertension. In addition, among men having raised cholesterol and having completed primary education, and among women central obesity and hazardous or harmful alcohol use were positively associated with hypertension (Table 4).

\section{Discussion}

In this first nationally representative population-based survey on hypertension in Laos, the prevalence of hypertension in adults (18-64 years) was $20.0 \%$ in 2013, which is similar to the prevalence among 25- to 64-year olds in the 2008 Lao STEP survey in nine health districts of Vientiane Capital City (22.3\%). ${ }^{3}$ This figure is lower than in the Myanmar survey in 2009 of $30.1 \%$ in 15 - to 64 -year olds, ${ }^{9} 22.0 \%$ in Thailand (15 years and older in 2004) $)^{11}$ and the China survey in 2010 of $29.6 \%$ in individuals 18 years and older, ${ }^{13}$ and the global adult ( $\geq 20$ years) prevalence in low- and middle-income countries (31.5\%), ${ }^{37}$ similar to the prevalence of hypertension in Iran (25- to 64-year olds), ${ }^{14,38}$ Sri Lanka ( $\geq 18$ years), ${ }^{11}$ and

Table 3 Awareness and treatment pattern for hypertension by age group among 2,543 adults in the Laos STEPS Survey, 2013

\begin{tabular}{|c|c|c|c|c|c|c|c|}
\hline \multirow[t]{3}{*}{ Total sample } & \multirow[b]{2}{*}{ Total } & \multicolumn{5}{|c|}{ Age groups in years } & \multirow[t]{2}{*}{$P$-value } \\
\hline & & $18-24$ & $25-34$ & $35-44$ & 45-54 & $55-64$ & \\
\hline & (\%) & $(\%)$ & (\%) & (\%) & (\%) & $(\%)$ & \\
\hline Ever blood pressure measured by healthcare worker & 39.9 & 29.4 & 34.2 & 42.8 & 45.7 & 47.7 & $<0.001$ \\
\hline $\begin{array}{l}\text { Ever previously diagnosed with raised blood pressure or } \\
\text { hypertension }\end{array}$ & 8.9 & 3.4 & 4.7 & 7.5 & 13.0 & 18.0 & $<0.001$ \\
\hline Hypertension measured & 16.7 & 5.3 & 9.2 & 17.3 & 23.8 & 30.2 & $<0.001$ \\
\hline Hypertension measured and/or treated & 20.0 & 8.4 & 12.0 & 20.7 & 27.5 & 33.8 & $<0.001$ \\
\hline \multicolumn{8}{|l|}{ Of hypertensives } \\
\hline Aware & 29.3 & 5.4 & 19.5 & 19.8 & 36.0 & 42.9 & $<0.001$ \\
\hline Treated (drugs, medication) & 18.2 & 5.4 & 14.4 & 6.5 & 21.8 & 30.8 & $<0.001$ \\
\hline Controlled & 16.7 & 37.8 & 24.0 & 16.4 & 13.5 & 10.6 & 0.006 \\
\hline \multicolumn{8}{|l|}{ Aware of hypertension } \\
\hline Treated (drugs, medication) & 49.9 & 62.7 & 40.3 & 26.7 & 51.6 & 64.3 & 0.011 \\
\hline Advice to reduce salt & 72.6 & 67.6 & 53.8 & 65.8 & 81.2 & 76.3 & 0.141 \\
\hline Advice or treatment to lose weight & 72.6 & 89.9 & 58.6 & 66.6 & 76.3 & 74.4 & 0.286 \\
\hline Advice or treatment to stop smoking & 42.2 & 36.7 & 14.7 & 37.3 & 47.7 & 52.9 & 0.043 \\
\hline Advice to start or do more exercise & 65.4 & 73.6 & 46.0 & 62.3 & 76.2 & 61.6 & 0.188 \\
\hline Ever traditional healer & 26.7 & 18.9 & 17.4 & 32.7 & 26.7 & 28.3 & 0.738 \\
\hline Currently taking herbal or traditional remedy & 12.8 & 0.0 & 0.0 & 22.6 & 12.1 & 15.5 & 0.090 \\
\hline \multicolumn{8}{|l|}{ Of treated } \\
\hline Controlled & 17.1 & 21.2 & 40.1 & 0.0 & 18.7 & 13.4 & 0.251 \\
\hline
\end{tabular}


Table 4 Predictors of hypertension by gender

\begin{tabular}{|c|c|c|c|c|}
\hline \multirow[t]{2}{*}{ Variables } & \multicolumn{2}{|l|}{ Men } & \multicolumn{2}{|l|}{ Women } \\
\hline & COR $(95 \% \mathrm{Cl})^{\mathrm{a}}$ & AOR $(95 \% \mathrm{Cl})^{b}$ & $\operatorname{COR}(95 \% \mathrm{Cl})^{\mathrm{a}}$ & AOR $(95 \% \mathrm{Cl})^{\mathrm{b}}$ \\
\hline \multicolumn{5}{|l|}{ Sociodemographics } \\
\hline \multicolumn{5}{|l|}{ Age in years } \\
\hline $18-34$ & I (Reference) & I (Reference) & I (Reference) & I (Reference) \\
\hline $35-49$ & $2.63(1.64,4.25)^{* * *}$ & $1.86(1.07,3.26)^{*}$ & $2.22(1.52,3.24)^{* * *}$ & $1.70(1.13,2.55)$ \\
\hline $50-64$ & $4.92(3.03,7.98)^{* * *}$ & $3.66(1.98,6.76)^{* * *}$ & $4.07(2.78,5.96)^{* * *}$ & $3.12(2.04,4.76)^{* * *}$ \\
\hline \multicolumn{5}{|l|}{ Education } \\
\hline No formal education/less than primary & I (Reference) & I (Reference) & I (Reference) & --- \\
\hline Primary & $2.50(1.46,4.28)^{* * *}$ & $2.02(1.12,3.64)^{*}$ & $0.90(0.65,1.24)$ & \\
\hline Secondary or more & $2.37(1.40,4.01)^{* * *}$ & $1.84(0.95,3.57)$ & $1.08(0.77,1.49)$ & \\
\hline Employed (base $=$ not employed) & $1.6 \mathrm{I}(\mathrm{I} .08,2.4 \mathrm{I})^{*}$ & $0.95(0.59,1.52)$ & $1.04(0.78,1.39)$ & --- \\
\hline \multicolumn{5}{|l|}{ Marital status } \\
\hline Never married & I (Reference) & I (Reference) & I (Reference) & I (Reference) \\
\hline Married or cohabiting & $2.43(1.20,4.91)^{*}$ & $1.22(0.50,3.01)$ & $2.14(1.10,4.16)^{*}$ & $\mathrm{I} .14(0.56,2.33)$ \\
\hline Separated, divorced, widowed & $3.95(1.07,14.52)^{*}$ & $2.40(0.68,8.81)$ & $4.43(1.95,10.07)^{* * *}$ & $\mathrm{I} .84(0.74,4.6 \mathrm{I})$ \\
\hline Ethno-linguistic group (Lao-Tai) (base = other) & $2.78(1.79,4.30)^{* * *}$ & $1.36(0.77,2.40)$ & $1.82(1.27,2.62)^{* * *}$ & $1.18(0.80,1.73)$ \\
\hline Urban residence (base $=$ rural residence) & $2.08(1.39,3.12)^{* * *}$ & $1.36(0.88,2.12)$ & $1.52(1.12,2.07)^{* *}$ & $1.26(0.90,1.75)$ \\
\hline \multicolumn{5}{|l|}{ Body weight status and health behavior } \\
\hline \multicolumn{5}{|l|}{ Body mass index } \\
\hline Normal & I (Reference) & I (Reference) & I (Reference) & I (Reference) \\
\hline Underweight & $0.60(0.18,1.95)$ & $0.61(0.18,2.04)$ & $0.62(0.32,1.23)$ & $0.60(0.29,1.24)$ \\
\hline Overweight & $2.53(1.60,4.03)^{* * *}$ & $2.44(1.48,4.02)^{* * *}$ & $1.82(1.21,2.74)^{* *}$ & $1.38(0.86,2.15)$ \\
\hline Obese & $4.55(2.73,7.56)^{* * *}$ & $2.42(1.19,4.92)^{*}$ & $3.82(2.73,5.34)^{* * *}$ & $2.03(1.27,3.22)^{* *}$ \\
\hline Central obesity & $4.63(2.91,7.36)^{* * *}$ & $1.63(0.87,3.06)$ & $3.66(2.80,4.79)^{* * *}$ & $1.83(1.25,2.67)^{* *}$ \\
\hline Fruit and vegetable consumption ( $<5$ servings) & $0.74(0.44,1.25)$ & --- & $1.22(0.78,1.91)$ & --- \\
\hline Meals prepared outside home (once or more/week) & $1.35(0.90,2.03)$ & --- & $\mathrm{I} . \mathrm{II}(0.8 \mathrm{I}, \mathrm{I} .53)$ & --- \\
\hline \multicolumn{5}{|l|}{ Oil or fat used for cooking } \\
\hline None & I (Reference) & I (Reference) & I (Reference) & I (Reference) \\
\hline Vegetable oil & $3.18(1.57,6.45)^{* * *}$ & $2.16(0.99,4.72)$ & $1.67(1.01,2.73)^{*}$ & $1.14(0.69,1.88)$ \\
\hline Lard or suet, butter or ghee & $1.59(0.72,3.54)$ & $1.72(0.76,3.93)$ & $1.32(0.74,2.35)$ & $1.26(0.70,2.26)$ \\
\hline Physical activity (high) (base = low $/$ moderate) & $0.64(0.46,0.91)^{*}$ & $1.01(0.64,1.58)$ & $0.69(0.36,1.31)$ & --- \\
\hline High sitting time & $1.86(0.76,4.57)$ & --- & $1.32(0.69,2.54)$ & --- \\
\hline Current tobacco use & $0.73(0.5 \mathrm{I}, \mathrm{I} .02)$ & --- & $0.73(0.48,1.10)$ & --- \\
\hline Hazardous or harmful alcohol use & $1.15(0.56,2.39)$ & --- & $2.84(1.22,6.55)^{*}$ & $3.14(1.36,7.24)^{* *}$ \\
\hline \multicolumn{5}{|l|}{ Biochemical } \\
\hline Raised cholesterol $(\geq 5.0 \mathrm{mmol} / \mathrm{L})$ or medication & $3.47(2.24,5.37)^{* * *}$ & $1.67(1.03,2.76)^{*}$ & $2.16(1.61,2.88)^{* * *}$ & $1.36(0.97,1.89)$ \\
\hline Raised fasting blood glucose $(\geq 6.1 \mathrm{mmol} / \mathrm{L})$ or medication & $1.56(0.78,3.09)$ & --- & $2.69(1.7 I, 4.18)^{* * *}$ & $1.53(0.92,2.56)$ \\
\hline
\end{tabular}

Notes: ${ }^{A} A d j u s t e d$ for age; ' adjusted for all covariates. ${ }^{*} * P<0.00 I,{ }^{*} * P<0.01,{ }^{*} P<0.05$.

Abbreviations: AOR, adjusted odds ratio; COR, crude odds ratio.

Vietnam ( $\geq 25$ years), ${ }^{12}$ but higher than in Cambodia ( $15.3 \%$ in 25- to 64-year olds). ${ }^{7}$

Of those who had hypertension, only $29.3 \%$ were aware and $18.2 \%$ were using antihypertensive medication. Similarly, among 25- to 64-year-old hypertensives in the 2008 Lao STEP survey in nine health districts of Vientiane Capital City, $16.2 \%$ were on antihypertensive medication. ${ }^{3}$ The proportion of awareness was lower in this study compared to figures reported from China, ${ }^{13}$ Vietnam,${ }^{12}$ and globally in low- and middle-income countries, ${ }^{15,37}$ and the proportion of reported treatment was also significantly lower in this study than in other countries, including China, ${ }^{13}$ Iran,${ }^{14}$ Vietnam, ${ }^{12}$ and globally in low- and middle-income country studies. ${ }^{15,37}$ The awareness and treatment of hypertension was in this study greater among women than men, as reported previously. ${ }^{16}$ These results suggest that awareness and treatment of hypertension needs to be strongly improved, particularly among men.

This study found, in agreement with various studies, ${ }^{9-12,14-16}$ that older age (among both men and women) was associated with hypertension. Previous studies ${ }^{9,12}$ found an association between urban residence and hypertension, while this study found this association only in bivariate analysis. Regarding weight variables, general obesity increased the odds of having 
hypertension in men and women. The relationship between obesity and hypertension has been confirmed in several previous studies. ${ }^{9,13,15-17}$ Obesity may be associated with hypertension independently but it could also be mediated through unhealthy diet and inadequate physical activity. ${ }^{14}$ Other metabolic risk factors for hypertension include diabetes ${ }^{17-19}$ and dyslipidemia, ${ }^{19,20}$ while in this study only in bivariate analysis among women an association between diabetes and hypertension was found, and among men an association between dyslipidemia and hypertension was found.

As found in a number of previous studies, ${ }^{9,13,27}$ bivariate analysis in this study also indicated that high physical activity among men but not among women was negatively associated with hypertension. The elevated blood pressure among the women participants of the study may not be attributable to physical inactivity but might be related to other factors such as obesity. ${ }^{39}$

Unlike previous studies, ${ }^{21-26}$ this study did not find an association between fruit and vegetable, saturated fat, fast food consumption (having meals prepared outside the home) and hypertension. Current tobacco use is a significant risk factor for hypertension. ${ }^{28}$ However, in this study no association was found. It is possible that the impact of current tobacco use on hypertension is delayed, and thus, current tobacco use may not be closely correlated with hypertension. ${ }^{40}$ In a "life-course impact of smoking on hypertension" study, Gao et $\mathrm{al}^{40}$ found that current number of cigarettes smoked per day was negatively associated with the risk of hypertension; however, the increase of "life-course-adjusted number of cigarettes smoked per day" was associated with higher risks of hypertension. This study found, in agreement with previous studies, ${ }^{13,29}$ that hazardous or harmful alcohol use was among women was associated with hypertension.

\section{Limitations}

Apart from blood chemistry, blood pressure, and anthropometric assessments, a study limitation was that the information assessed by questionnaire was based on self-report. Certain behaviors, such as substance use, may have been over- or under-reported. This study was cross-sectional, which hinders to establish causal relationships between risk factors and the development of hypertension. Another limitation was that salt intake, which is a determinant of hypertension, was not assessed in this study.

\section{Conclusion}

The study found a significant prevalence of hypertension in a representative sample of the general adult population in Laos. Less than one-third of hypertensives were aware and a minority were treated and controlled. Several risk factors, including sociodemographic variables (older age, completion of primary school), body weight status (obesity), health behavior (hazardous or harmful alcohol use), and raised cholesterol levels have been identified, which can facilitate in guiding hypertension control programs. Interventions strategies that operate at multiple levels are needed that can increase awareness of hypertension, access to high blood pressure treatment, and community-wide health promotion interventions that were identified and known to be effective in reducing high blood pressure levels. Future studies may want to include additional measures such as salt intake consumption.

\section{Acknowledgment}

The WHO supported this survey.

\section{Author contributions}

All authors contributed toward data analysis, drafting and critically revising the paper, gave final approval of the version to be published, and agree to be accountable for all aspects of the work.

\section{Disclosure}

The authors report no conflicts of interest in this work.

\section{References}

1. World Health Organization (WHO). Global Status Report On Noncommunicable Diseases 2014. Geneva, Switzerland: WHO; 2014.

2. Ibrahim MM, Damasceno A. Hypertension in developing countries. Lancet. 2012;380(9841):611-619.

3. Vang C, Melanie C, Phoxay C, et al. Report on STEPS Survey on Non Communicable Diseases Rick Factors in Vientiane Capital city, Lao PDR, 2010. Available from: www.who.int/ncds/surveillance/ steps/2008_STEPS_Report_Laos.pdf. Accessed June 12, 2018.

4. Vang C. The burden of hypertension in the Lao PDR. Lao Med J. 2010;1:36-39.

5. Loo KW, Gan SH. The burden of stroke in the Lao People's Democratic Republic. Int J Stroke. 2013;8:273-275.

6. NCD Risk Factor Collaboration (NCD-RisC). Worldwide trends in blood pressure from 1975 to 2015: a pooled analysis of 1479 populationbased measurement studies with $19 \cdot 1$ million participants. Lancet. 2017;389(10064):37-55.

7. Gupta V, Logerfo JP, Raingsey PP, Fitzpatrick AL. The prevalence and associated factors for prehypertension and hypertension in Cambodia. Heart Asia. 2013;5(1):253-258.

8. Naing C, Yeoh PN, Wai VN, Win NN, Kuan LP, Aung K. Hypertension in Malaysia: an analysis of trends from the national surveys 1996 to 2011. Medicine (Baltimore). 2016;95(2):e2417.

9. Bjertness MB, Htet AS, Meyer HE, et al. Prevalence and determinants of hypertension in Myanmar - a nationwide cross-sectional study. BMC Public Health. 2016;16:590.

10. Katulanda P, Ranasinghe P, Jayawardena R, Constantine GR, Rezvi Sheriff MH, Matthews DR. The prevalence, predictors and associations of hypertension in Sri Lanka: a cross-sectional population based national survey. Clin Exp Hypertens. 2014;36:484-491. 
11. Aekplakorn W, Abbott-Klafter J, Khonputsa P, et al. Prevalence and management of prehypertension and hypertension by geographic regions of Thailand: the third National health Examination Survey, 2004. $J$ Hypertens. 2008;26(2):191-198.

12. Son PT, Quang NN, Viet NL, et al. Prevalence, awareness, treatment and control of hypertension in Vietnam-results from a national survey. J Hum Hypertens. 2012;26(4):268-280.

13. Wang J, Zhang L, Wang F, Liu L, Wang H. China national survey of chronic kidney disease Working Group. Prevalence, awareness, treatment, and control of hypertension in China: results from a national survey. Am J Hypertens. 2014;27:1355-1361.

14. Esteghamati A, Abbasi M, Alikhani S, et al. Prevalence, awareness, treatment, and risk factors associated with hypertension in the Iranian population: the National survey of risk factors for noncommunicable diseases of Iran. Am J Hypertens. 2008;21(6):620-626.

15. Chow CK, Teo KK, Rangarajan S, et al; PURE (Prospective Urban Rural Epidemiology) Study investigators. Prevalence, awareness, treatment, and control of hypertension in rural and urban communities in high-, middle-, and low-income countries. JAMA. 2013;310:959-968.

16. Hussain MA, Mamun AA, Reid C, Huxley RR. Prevalence, awareness, treatment and control of hypertension in Indonesian adults aged $\geq 40$ years: findings from the Indonesia family life Survey (IFLS). PLoS One. 2016;11(8):e0160922.

17. Naly N, Sanong T, Vang C, Mayfong M. Risk factors associated with hypertension among Lao adults in Vientiane, Laos. Lao Med J. 2010;1:40-45.

18. Rahman M, Zaman MM, Islam JY, et al. Prevalence, treatment patterns, and risk factors of hypertension and pre-hypertension among Bangladeshi adults. J Hum Hypertens. 2018;32:334-348.

19. Gupta V, LoGerfo JP, Raingsey PP, Fitzpatrick AL. The prevalence and associated factors for prehypertension and hypertension in Cambodia. Heart Asia . 2013;5(1):253-258.

20. Soubeiga JK, Millogo T, Bicaba BW, Doulougou B, Kouanda S Prevalence and factors associated with hypertension in Burkina Faso: a countrywide cross-sectional study. BMC Public Health. 2017;17:64.

21. Li B, Li F, Wang L, Zhang D. Fruit and vegetables consumption and risk of hypertension: a meta-analysis. J Clin Hypertens (Greenwich). 2016;18:468-476

22. Wang L, Manson JE, Gaziano JM, Buring JE, Sesso HD. Fruit and vegetable intake and the risk of hypertension in middle-aged and older women. Am J Hypertens. 2012;25:180-189.

23. Zhao D, Qi Y, Zheng Z, et al. Dietary factors associated with hypertension. Nat Rev Cardiol. 2011;8:456-465.

24. Ezekwesili CN, Ononamadu CJ, Onyeukwu of, Mefoh NC. Epidemiological survey of hypertension in Anambra state, Nigeria. Niger J Clin Pract. 2016;19:659-667.

25. El-Badawy AM, Al-Kharusi HM, Al-Ghanemy SA. Health habits and risk factors among Omanis with hypertension. Saudi Med J. 2005;26(4):623-629.
26. Xu X, Byles J, Shi Z, McElduff P, Hall J. Dietary pattern transitions, and the associations with BMI, waist circumference, weight and hypertension in a 7-year follow-up among the older Chinese population: a longitudinal study. BMC Public Health. 2016;16:743.

27. Börjesson M, Onerup A, Lundqvist S, Dahlöf B. Physical activity and exercise lower blood pressure in individuals with hypertension: narrative review of 27 RCTs. Br J Sports Med. 2016;50:356-361.

28. Leone A. Smoking and hypertension: independent or additive effects to determining vascular damage? Curr Vasc Pharmacol. 2011;9(5): 585-593.

29. Miller PM, Anton RF, Egan BM, Basile J, Nguyen SA. Excessive alcohol consumption and hypertension: clinical implications of current research. J Clin Hypertens (Greenwich). 2005;7:346-351.

30. Vonglokham M, Kounnavong S, Sychareun V, Pengpid S, Peltzer K. The prevalence and social and health determinants of pre-diabetes and diabetes among adults in Laos: a cross-sectional national populationbased survey, 2013. Trop Med Int Health. 2019;24(1):65-72.

31. World Health Organization. STEP wise approach to noncommunicable disease risk factor surveillance (STEPS). Available from: http://www. who.int/chp/steps/riskfactor/en/. Accessed March 18, 2018.

32. World Health Organization. Global Physical Activity Questionnaire (GPAQ) Analysis Guide. Geneva: World Health Organization; 2012.

33. Force U. Screening and behavioral counseling interventions in primary care to reduce alcohol misuse: recommendation statement. Ann Intern Med. 2004;140:554-556.

34. Wen CP, David Cheng TY, Tsai SP, et al. Are Asians at greater mortality risks for being overweight than Caucasians? Redefining obesity for Asians. Public Health Nutr. 2009;12(4):497-506.

35. World Health Organization (WHO). Waist circumference and waist-hip ratio report of a WHO expert consultation Geneva, 8-11 December 2008; 2011. Available from: http://whqlibdoc.who.int/publications/20 11/9789241501491eng.pdf. Accessed May 15, 2018.

36. Chobanian AV, Bakris GL, Black HR, et al. Seventh report of the joint national committee on prevention, detection, evaluation, and treatment of high blood pressure. Hypertension. 2003;42(6):1206-1252.

37. Mills KT, Bundy JD, Kelly TN, et al. Global disparities of hypertension prevalence and control: a systematic analysis of population-based studies from 90 countries. Circulation. 2016;134:441-450.

38. Hosseini M, Yousefifard M, Baikpour M, et al. Twenty-year dynamics of hypertension in Iranian adults: age, period, and cohort analysis. J Am Soc Hypertens. 2015;9:925-934.

39. Krauss RM, Winston M, Fletcher BJ, Grundy SM. Obesity: impact on cardiovascular disease. Circulation. 1998;98:1472-1476.

40. Gao K, Shi X, Wang W. The life-course impact of smoking on hypertension, myocardialinfarction and respiratory diseases. Sci Rep. 2017;7:4330.
Vascular Health and Risk Management

\section{Publish your work in this journal}

Vascular Health and Risk Management is an international, peerreviewed journal of therapeutics and risk management, focusing on concise rapid reporting of clinical studies on the processes involved in the maintenance of vascular health; the monitoring, prevention and treatment of vascular disease and its sequelae; and the involvement of

\section{Dovepress}

metabolic disorders, particularly diabetes. This journal is indexed on PubMed Central and MedLine. The manuscript management system is completely online and includes a very quick and fair peer-review system, which is all easy to use. Visit http://www.dovepress.com/ testimonials.php to read real quotes from published authors. 